the work itself. There are citations to the number of 423 , and more, not numbered, yet, although we have a long discussion on the relationship of Limulus to Scorpion, Lankester's work is not mentioned; with chapters on fresh-water faunas, no allusion to "The Origin of Freshwater Faunas," by Sollas; W. Marshall, a German author, is set forward in the text as an authority on pelagic and coast faunas, and Moseley overlooked ; titles are sometimes given without place or date of publication, a defect which becomes seriouts when periodical literature is referred to without mention of volume. The illustrations are numerous and excellent.

The author has produced a fresh and promising thought, but one cannot help regretting that he did not wait-like, say, Darwin-till it was full time for bringing forth.

W. J. SOllas.

\section{THE PHOTOGRAPHIC MAP OF THE} HEA VENS.

THE first number of the second volume of papers published under the auspices of the Permanent Committee charged with the execution of the photographic map of the sky has made its appearance at a sad moment in the history of the undertaking. For simultaneously with its appearance is announced the death of him who, more than any other man, has contributed to its success, and brought it within the range of practical science. Admirai Mouchez has known how to secure not only the active co-operation of many astronomers, but also how to make them zealous in the great work, the arrangement of the details of which has occupied the last years of his life. He has awakened enthusiasm for the success of his scheme, and smoothed many difficulties which might have hindered its progress, and probably few undertakings of equal magnitude and equal importance, breaking new ground in many directions, have been got under way with less friction and fewer disappointments. We may well hope that the same sauvity and diplomacy which has characterized the conduct of the late Director of the Paris Observatory will be found in the counsels of his successor, and that a work begun in so much hope will be carried to a successful issue.

The papers in the volume before us can be brought roughly under two heads, both, notwithstanding the lapse of time from the inception of the scheme, betokening an initial stage in the preparation. One of the topics under discussion has for its aim the selection of a method which shall secure on the photographic plates, destined ultimately to furnish a catalogue, the impression of stars of the eleventh magnitude with certainty and uniformity; the other, a means of deriving the co-ordinates of the star images so impressed with the greatest facility and sufficient accuracy.

To deal with the second of these proposals first, we may remind our readers that whatever method of measuring the positions of stars on a plate may be adopted, the resulting co-ordinates must be purely differential, and probably referred to the axes of the réseau impressed upon the plate as a latent image, and developed under the same conditions as the stars themselves. To pass to the determination of R.A. and declination, a great deal of information, entirely independent of photography, will have to be made available. The readiest means of effecting this last step in the reduction, as it appeared to a committee of experts appointed to consider this question, was to determine by meridian instruments the absolute co-ordinates of six stars on each plate. It is needless to comment upon the magnitude of the labour thus undertaken, or at least contemplated. This preliminary work would demand a catalogue of some sixty or seventy thousand stars, most of them below the ninth I "Bulletin du Comité International Permanent," tome ii., premier fascicule.

NO. I I 96 , VOL. 46$]$ magnitude and not found in existing catalogues. In order to give to each determination the necessary accuracy, it is desirable that each star should be observed twice in both elements and at two observatories. When we remember the length of time that the re-observation of Argelander's zones has consumed, and is still incomplete, we can form some estimate of the time that must inevitably elapse before the results of the photographic catalogue can be made available for astronomical purposes.

In presence of these difficulties, and many more which occur to the practical astronomer, we must be very grateful to M. Loewy for elaborating a scheme which, if it be found practicable, will materially shorten the time necessary for the production of the catalogue. M. Loewy proposes to avail himself of the fact that the plates are taken in two series, in such a manner that each corner of a plate in one series will form the centre of four other plates in the second series. When, therefore, the astronomer has determined the rectilinear co-ordinates of the stars on one plate relatively to the central lines of the réseau, each of these stars will belong in common to the plate considered, and to one of the four plates of the second series, partially covering the first. M. Loewy's scheme consists in making the stars on the four plates thus connected available for the reduction of the first. And, on paper at least, it is not difficult to extend the scheme still further, and to make the plates contiguous to these four contribute to the reduction of the original plate by means of an extended triangulation. In this way a plate would not be considered as an isolated fact, but a considerable area, of $36,64,100$ or more square degrees could be woven into a harmonious scheme of reduction. And such a plan possesses this very obvious advantage, that on even a lesser area, as of 36 square degrees, we may well expect to meet a sufficient number of bright stars whose places are already so well determined that the reduction of the plates could go on immediately without waiting for the observations of the stars on the meridian. And independently of this evident advantage, it seems highly probable that two of the elements of reduction, viz. the orientation of the plate, and the value of the scale, will be determined more accurately, if the stars which are used for the derivation of these corrections are separated by a considerable distance, that is greater than a single negative would permit.

M. Loewy considers the various sources of errors and their necessary correction with all the detail required to submit the plan to practical application, and this is precisely the test that is needed. This appears to be also the opinion of Dr. Gill, expressed in a very cautious approval of M. Loewy's scheme, and he further quotes a remark of Prof. Auwers, which contains a very salutary caution. That astronomer points out that the reduction of the catalogue plates will be most accurately effected from the position of faint stars, rather than from bright ones. In that case since our present most accurate catalogues do not give the positions of the fainter stars, those catalogues will still need to be supplemented by many meridian observations. Dr. Sande Bakhuyzen, however, expresses the opinion that the zones of the Astronomische Gesellschaft will, when completed, furnish the necessary data for all reductions, or, at most, require additional observations in some portions of the sky, which he is able to point out from a careful examination of the number of the stars contained in these zones.

The second topic which has received much consideration in this volume is, as before mentioned, the adoption of a method to secure the registration of stars of the eleventh magnitude. It will be remembered that the International Congress of 1891 proposed to place in front of the object glass of the telescope, screens of fine metallic gauze, identical in manufacture, and of such construction that the amount of light impeded should be equivalent to two magnitudes: the coefficient 2.512 being employed as 
the ratio to express the relative brilliancy between two consecutive magnitudes. A committee was appointed to carry this plan into execution, but the report which this Committee has issued is unfavourable to the adoption of the method. The signatures of the Astronomer Royal, Prof. Pritchard, and the brothers Henry, are attached to this report; but $M$. Vogel, the remaining member of the Committee, has not found the reasons assigned by his colleagues sufficient to warrant the rejection of the scheme, and consequently his name does not appear. The President of the Permanent Committee thus sums up the case against the proposal. Light in traversing a metallic screen of bright threads and very narrow mesh, seems to experience, besides the ordinary effects of diffraction, certain modifications, whose cause is not yet explained, and which the Congress could not foresee when they framed the recommendation. This peculiar behaviour of the light demands further study, and renders the application of this means very difficult, if not useless, for the purpose for which it was proposed, since the discrepancies of the results obtained are greater than the error that an experienced astronomer would make in estimating stars of the eleventh magnitude.

The experiments on which this conclusion is founded are set out in considerable detail, and a careful study of these experiments ought to convince an unprejudiced critic that the committee was justified in advising the rejection of the screens as an adequate and efficient means of deciding upon stars of the eleventh magnitude. It should be stated that the gauze screens, identical in character, were furnished by Prof. Vogel, and though there is no mention of the experiments or processes which induced the Potsdam astronomers to select a screen of this particular obstructive power, it is to be presumed that in his photographic telescope they stopped the amount of light proposed by the Congress. It is not the least curious feature in the discussion (controversy would be far too strong a word to describe the courteous paragraphs in which the various astronomers set forth their reasons for dissent from the able physicist), that Prof. Vogel takes no part in it nor vouchsafes any information as to the principles by which he was guided in the selection, but leaves the onus of rejection entirely to his colleagues, who are thus placed at a disadvantage.

Prof. Pritchard, whose photometric researches permit him to speak with authority, has stated concisely the result of his experience. He found that on the ordinary astronomical telescope, achromatised presumably for $D$, the amount of light obstructed was equivalent to $2.4 \mathrm{mag}$., and on the photographic telescope, with a minimum focal length for $G$, the amount of light lost was not less than $2.8 \mathrm{mag}$. The Astronomer-Royal reports that the action of the screen on the Greenwich telescope is to stop 2.5 mag. This result was deduced by comparing the seventh and ninth magnitude stars of Argelander. Some further comparisons of the obstructed and unobstructed light of stars of the ninth and eleventh magnitude photometrically examined by Prof. Pritchard with the wedge photometer confirmed this result, and further proved that the scale of Pritchard and Argelander was in very satisfactory and close agreement. It will be necessary to return to this point. M. Henry at Paris offers results in close accordance with those of the two English astronomers just quoted. He finds that the screen proposed by M. Vogel as effective in his instrument stops between 2.5 and 2.7 mag. on the Paris telescope, and this effect is still further confirmed by some observations by $\mathrm{M}$. Trépied, while M. Rayet at Bordeaux finds $27 \mathrm{mag}$. represents the effective action of the screen. Very different is the experience of M. Donner, of Helsingfors. His method of estimating the loss of light is different from that employed in the other cases, and is perhaps not without objection, but the result which he derives from his observations is that NO. I I 86 , VOL. 46$]$ the light of a star in passing through the screen loses only i. 6 mag.

It is now necessary to describe very briefly the methods employed in the various observatories which have led to these discordant results, the more so as one eminent authority, Dr. Dunér, of Lund, who apparently holds a brief for Prof. Vogel, has taken exception to the results deduced. Leaving on one side the experiments conducted by MM. Henry and Trépied on artificial stars, and against which Dr. Dunér urges no objection further than that they are founded on artificial stars, we find that one principle pervades the examination conducted at Greenwich, Paris, Bordeaux, and Algiers. The several astronomers have determined what length of time is necessary to produce a blackened star disc of the same diameter from the same star with and without the screen. In this way it has been found necessary to expose for ten or eleven times as long with the screen before the object glass as without, and from this fact it has been inferred that the loss of light occasioned by the screen amounts to 2.5 or 2.6 mag. It is urged that if only two magnitudes were lost by obstruction, the necessary exposure would have been $(2.512)^{2}=6.3$, that required by the unobstructed object glass. Dr. Dunér remarks on this that those who have condemned the employment of the screens on these grounds have argued in a vicious circle, and to be logically correct it would be necessary to show that the intensity varies as the time of exposure or

$$
i t=\text { const. }
$$

Against the accuracy of this law Dr. Duner urges that reports of the observers themselves show three distinct proofs. In the first place (I) Dr. Donner states that only $0.58 \mathrm{mag}$. is gained by successively multiplying the length of exposure by $25 ;(2)$ that the Astronomer Royal proves. that a gain of $I \cdot 7$ or $I .85 \mathrm{mag}$. is secured by multiplying the length of exposure by 6.25 ; and (3) that M M. Henry have found that to obtain similar discs from stars of the 9.3 and II. 3 mag. the exposure has to be increased from $28 \mathrm{sec}$. to $240 \mathrm{sec}$. ( $1: 8.6$ ). These three experiments give instead of 2.512 respectively,

$$
3 \cdot 28,2 \cdot 69,2 \cdot 93 \text {. }
$$

results apparently incompatible with the formula

$$
\text { it }=\text { const. }
$$

MM. Trépied and Henry reply at length and effectively to these strictures. They do not regard 2.69 and 2.93 as differing so greatly from 2.512 but that the discrepancy may be fully explained by inaccuracy and paucity of observations. The Helsingfors result $(3 \cdot 28)$ they refuse to accept as unequivocal evidence in the face of established facts. The method of Dr. Donner consisted in comparing photographs of the Pleiades, taken with and without the screen, with the map of $M$. Wolf, and marking the number and magnitude of the stars which have black or grey images. This method, as already hinted, does not seem to be entirely free from objection. Admitting that the comparison of the images was made, as we are sure it was, with all the care possible, there is still room for the varying exercise of individual judgment as to what constitutes a black and what a grey image, and the final result is likely to be less exact than a process based upon rigorous measurement.

The method employed by Prof. Pritchard is, perhaps, as free as any from objection or misinterpretation. He exposed the plate for equal times with and without the screen, and then measured the diameters of the resulting star discs. If two discs, produced, one with, and one without the screen, were found equal in diameter, then the effect of the screen is equivalent in photographic action to the original difference of magnitude between the two stars. This difference of magnitude was determined by the wedge photometer, and the only exception 
that can be taken to this determination is that the scale of the wedge photometer may not be accurately applicable. But here we have the distinct assertion of the Astronomer Royal, reiterated again by $M$. Trépied, that the Pritchard Argelander scales are in very satisfactory accord. This circumstance is the more gratifying for two reasons First, because it is distinctly stipulated in resolution 19 (I889), "Chaque observateur devra s'attacher à obtenir sur ses clichés destinés au catalogue la grandeur I I O déterminée aussi exactement que possible au moyen do l'échelle d'Argelander." The maintenance, therefore, of the scale of Argelander becomes of paramount importance, and this one could scarcely hope to effect by means of the gauze screens. The second satisfactory point is, that Prof. Pritchard is endeavouring to secure uniformity in the photographed stars by distributing among the participating observatories small charts of particular regions of the sky on which are marked stars of the gth and IIth magnitudes approximately. Naturally in the determination of the magnitudes of the stars on these charts, the scale of Argelander will be perpetuated, and inasmuch as the testimony of several astronomers is distinctly in favour of making use of these typical areas, it seems very probable that Argelander magnitudes will be prolonged in the catalogue work down to the faintest stars impressed.

\section{NOTES.}

THE summer meeting of the Institution of Mechanical Engineers will be held in Portsmouth, and will begin on Túesday, July 26. The following papers have been offered for reading and discussion, not necessarily in the order here given :On shipbuilding in Portsmouth dockyard, by Mr. William $\mathrm{H}$. White, F.R.S.; on the applications of electricity in the Royal dockyards and navy, by Mr. Henry E. Deadman; description of the lifting and hauling appliances in Portsmouth dockyard, by Mr. John T. Corner, R.N. ; description of the new Royal pier at Southampton, by Mr. Jame; Lemon; description of the Portsmouth sewage outfall works, by Sir Frederick Bramwell, F.R.S., Past-President; description of the new floating bridge between Portsmouth and Gosport, by Mr. H. Graham Harris; description of the Southampton sewage precipitation works and refuse destructor, by Mr. William B. G. Bennett; description of the experimental apparatus and shaping machine for ship models at the Admiralty experiment works, Haslar, by Mr. R. Edmund Froude; description of the pumping engines and water softening machinery at the Southampton water works, by Mr. William Matthews.

THE half-yearly general meeting of the Scottish Meteorological Society was held at Edinburgh on Monday, July I8. The council of the society submitted its report; and Dr. Buchan read a paper on variation in the annual rainfall in Scotland since 1800 ,

THE Museums Association held its annual meeting in Manchester, at the Owens College, on July 5, 6, and 7 , under the presidency of Prof. Boyd Dawkins, whose address we print elsewhere. Among those present at the meeting were Dr. Ward, Principal of Owens College, Prof. Flower, Prof. Miall, the Rev. Canon Hicks, Prof. Milnes Marshall, the Rev. H. H. Higgins, and Prof. Weiss. Mr. J. Willis Clark, the retiring president, was unfortunately prevented from attending. The following papers were read and discussed: -On the arrangement of botanical museums, by Prof. F. E. Weiss. - On the cultivation of special features in museums, by the Rev. H. H. Higgins, --Local museums of art and history, by the Rev. Canon Hicks.-On the Manchester Art Museum, by Mr. T. C. Horsfall. - On the preparation of picture catalogues, by Mr. Butler Wood.-On the colouring of the background of NO. I 186 , VOL. 46] museum cases, by Mr. Edgar R. Waite. - On the best means of preserving vegetable structures, and on a collection illustrating the life-histories of the British Lepidoptera, by Mr. J. W. Carr. -On the exclusion of dust, by Mr. T. Pridgin Teale; and library and museum legislation, by Mr. E. Howarth. Mr. Pacy and Mr. Ogle, who had been deputed by the Libraries' Association to attend the meeting, took part in the discussion of the last paper. A Committee of the Museums' Association was appointed to confer with the Libraries' Association on the possibility of taking steps to improve library and museum legislation. Most of the members of the Museums' Association who took part in the discussion were of opinion that the restrictions at present placed upon the action of Town Councils with regard to libraries and museums were unnecessary and obsolete. The meeting was a very successful one, thanks to the energy and good management of Mr. W. E. Hoyle and Prof. Milnes Marshall. The reception accorded to the Association by the authorities of the Owens College was of the most cordial nature, and the Association is indebted to Dr. Ward and several of his colleagues for much kindness. It was agreed to hold the next annual meeting in London under the presidency of Prof. Flower.

Mr. William E. Plummer has been appointed by the Mersey Docks and Harbour Board, director of the Liverpool Observatory, in the room of Mr. J. Hartnup, deceased. Hitherto this Observatory has done little more than regulate chronometers required for the port of Liverpool, but we understand that the Observatory will now be reorganized and made to play a more active part in observational astronomy, and one worthier of the equipment of the Observatory and the generous support the board accord to it.

DR. W. H. INCE, Ph.D. (Würzburg), Demonstrator of Chemistry in University College, Liverpool, has been appointed Demonstrator of Physics and Chemistry in the Medical School of St. Thomas's Hospital.

Mr. A. H. Leahy, M.A., Fellow of Pembroke College, Cambridge, has been elected to the Professorship of Mathematics at Firth College, Sheffield. Mr. Leahy is a Mathematical Lecturer and Junior Bursar of his College, and is the author of several important papers on mathematical physics.

Mr. R. Elliot STeel, Senior Science Master of the Bradford Grammar School, has been appointed by the Technical Instruction Committee of the Corporation of Plymouth to the Head Mastership of the Science Department of their new technical schools, Plymouth.

The Master and Wardens of the Drapers' Company of the City of London recently gave $£ 3000$ towards the erection of the new technical schools attached to the Nottingham University College, and have now given a further sum of $£$ Iooo towards their equipment.

"Cook's Tours" are well known all over the civilized world, and vast numbers of Englishmen have been indebted to them for some of the brightest and pleasantest experiences of their lives. Everyone, therefore, was sorry to hear of the death of Mr. Thomas Cook, the founder of the system. He died at Leicester on Monday in his eighty-fourth year. Mr. Cook was a man of immense energy, and may almost be said to have had a touch of genius. At all events he had a very remarkable faculty for organization, and dic much to foster among the British public a just appreciation of the advantages to be derived from foreign travel. Last year the jubilee of his firm was celebrated.

THE volcanic forces of Mount Etna have continued in a state of violent activity. On the afternoon of July $r_{4}$ it was stated, 